\title{
Health Care Reform and Expenditure Increase in China: A Province Level Study of Chinese Census Data
}

\author{
L. CHEN \\ School of Business, Jianghan University, Wuhan 430056, China
}

\begin{abstract}
Chinese government started the health care reform in 2000. The purpose of the reform is to provide better health care to the people living in China, as well as to make health care available to more residents. The first goal has been achieving gradually, yet the second one was compromised by the rapid increase of the out-of-pocket expenditure on health care. In this paper, we want to analyze the relationship between the increment of health care expenditure and other socioeconomic factors as the consequences of the health care reform, by using the Chinese Census data and the China Labor Statistical Yearbook (CLSY) data in province level. The results show that health care expenditure is correlated with income, household size, race, education level, age of residents, etc.
\end{abstract}

KEYWORD: Health Care Reform; Health Expenditure; Chinese Census Data

\section{INTRODUCTION}

From 1949 to 1978, the Peoples' Republic of China government provided free health care to all the workers who worked at the state-owned firms, which mostly located in urban area. Whereas in rural area, there were no free health care for farmers or hospitals, yet the so called "barefoot doctors" would provide very basic medical services to the local residents with minimum fees.

Starting from 1979, along with the economic reform in China, some county level community hospitals have been built up for people living in rural area, although they have to pay relatively high fees to get the services. While in urban area, more and more modern hospitals are in services for the residents. Therefore, in general people in China are getting better health services over the last 50 years.

However, these changes come with the cost of rapid increment of government expenditure on health care. Thus in late 1998, the central government announced the reform plan of health care system in China, and started implementing it in 2000. The foundational change according to the reform is that instead of government paying all the health care expenditure for workers in state-owned firms, government generates health insurance fund for all the employed workers in all kinds of firms. And the fund comes from the government, the firms, and the workers, where the firms pay most of the premium.

\section{LITERATURE REVIEW}

Chow [1] discussed the reform of health care reform in China and changes in health care institutions. He used the CLSY data to analyze both the demand and supply sides of health care in China. Then he evaluated the current health care system and showed that under such system the urban residents receive much better health services than rural residents. He thought one failure of the reform is that it failed to allow market force to operate in the supply of health care.

Guo and Wang [2] reviewed the health care system in China for the past 50 years and pointed out the achievement and failures in past as well as the current difficulties and challenges. They thought the current problems of the health care system include (i) there are still a lot of people who don't have health insurance, especially in rural area; (ii) the health care expenditure keep increasing rapidly; (iii) the supply of health care services can't meet the rising demand of the health care services. They suggest the government invest more on health care services and provide basic health insurance to people in rural area.

Wang et al [3] introduced the new reform of primary health care system announced by the government in 2006, and discussed the impartment role that family physicians could be in the new health care system. They also pointed out that "expensive to receive health care and inconvenient 
to access health care" have become two major complaints among Chinese people. There are a few other studies focused on this issue [4-5].

All the papers mentioned above used nation-wide data to show the challenge that current health care system faces due to the rapid increase of health care expenditure. In this paper, we will apply province level data to see the historical change of health care expenditure in each province and general relationship between health care expenditure and other social economic factors.

\section{DATA}

There are 31 provinces or directly governed districts in mainland China. From the CLSY data, I collect the data of insured population and covered health care expenditure for each province (excluding Tibet because of lack of data) in 1999, 2001, 2002, 2004, and 2006. I first calculate the health care expenditure per capita for each province and then get the weighted average (by population) for each geographic area and whole nation in each year.

Figure 1 shows the health care expenditure per capita (CPI adjusted) in each area in the selected years. These geographic areas include mid-north, mid-south, northeast, southeast, northwest, and southwest. We can see from the figure that for all areas the health expenditure dropped when the reform was just implemented in 2000 , and then gradually increasing and exceeding the level prior to the reform. This is because before the implementation of the reform, most employed workers had primary health care for free, so the total expenditure paid by the government was relatively high. Right after the reform, i.e., in year 2001, government stopped paying for all the health care expenditure. Instead, firms and their employees paid for most of it. Yet people have inertia to invest little on health insurance and incentive to spend less on health care. Thus the total expenditure on health care initial went down. Then, more people realized the importance of health insurance and invest more on it.

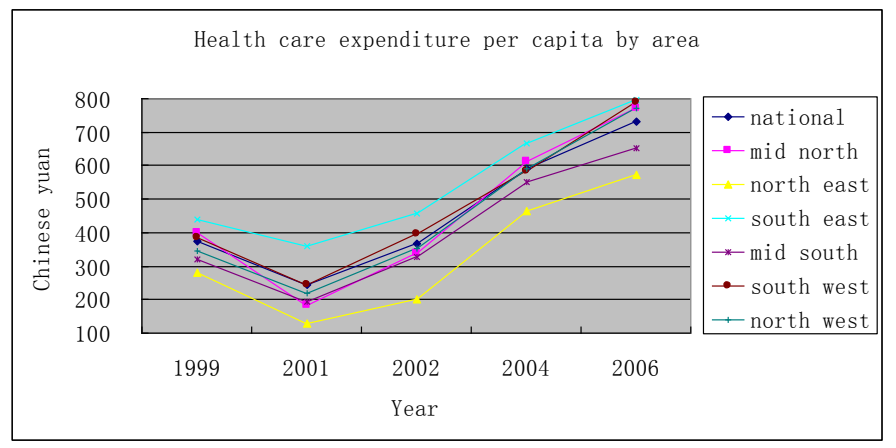

Figure 1: health care expenditure per capita

Also, people living in southeast pay highest amount per person for health care among all regions, partly because this area is the richest part in mainland China. Although people living in southeast pay lowest amount per person for health care among all regions, it is not the poorest region in China. So one possible explanation for the low expenditure of health care could be people in that area are on average healthier. It is true that native residents in that area are taller and stronger that residents in other areas in China. And since it's very cold in the winter there, the number of harmful viruses would be less than those warm and humid regions, just like Maine versus Taxes in the US.

Figure 2 shows the relationship between per capita annual income and expenditure on health care for each province in 2006.

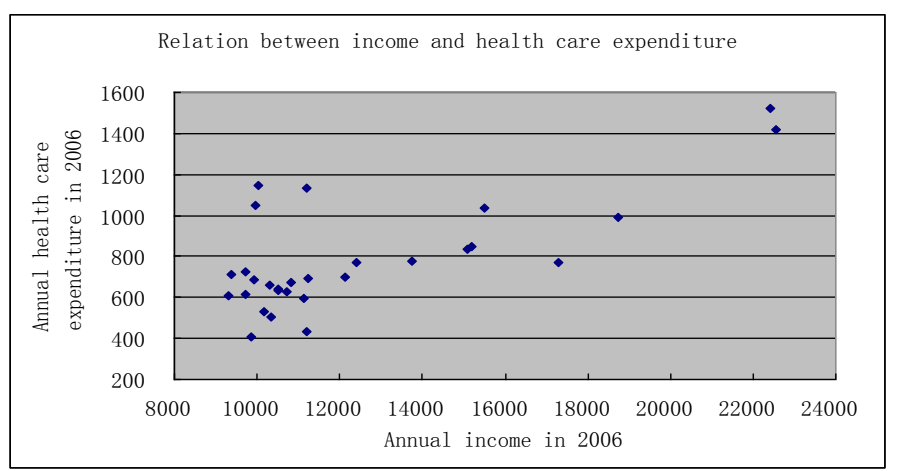

Figure 2: scatter plot of annual health care expenditure versus income

We can see that the expenditure on health care is positively related with the income.

\section{MODEL}

It is easy to understand that health care expenditure depends on income. But how and what other factors would affect the expenditure? In this paper, we assume health care expenditure are correlated with after tax income, number of people per household, percentage of senior residents, percentage of minority residents, and education level. We also assume linear relation between them so that we can write the model as the following:

$$
\operatorname{Exp}=\beta_{0}+\beta_{1} Y+\beta_{2} N+\beta_{3} S+\beta_{4} M+\beta_{5} E d u+e,
$$

where Exp is the annual expenditure on health care, $Y$ is annual after tax income, $N$ is number of people per household, $S$ is percentage of senior residents, $M$ is percentage of minority residents, $E d u$ is percentage of residents who have college education or above, and $e$ is the random error.

\section{EMPIRICAL ANALYSIS}

We use data from the CLSY and the Chinese Census data, and apply the ordinary least square (OLS) 
regression to estimate the coefficients of the data are given in the following table: explanation variables. The statistics of the sample

Table 1: Summary statistics

\begin{tabular}{|l|c|c|c|c|c|}
\hline Description & mean & median & std dev & $\max$ & $\min$ \\
\hline Annual expenditure on health care & 785 & 698 & 269 & 1525 & 409 \\
\hline Per capita after tax annual income & 11500 & 10194 & 3209 & 20300 & 8712 \\
\hline Number of residents per household & 3.49 & 3.53 & 0.33 & 4.06 & 2.80 \\
\hline Percentage of senior residents & 6.77 & 6.54 & 1.57 & 11.50 & 4.33 \\
\hline Percentage of minority residents & 12.64 & 4.98 & 16.44 & 59.39 & 0.01 \\
\hline \% of residents with college education & 4.38 & 3.33 & 3.23 & 17.50 & 1.90 \\
\hline Source: CLSY and Chinese Census & & & & \\
\hline
\end{tabular}

The table shows that the annual expenditure on health care is about $7 \%$ of the after tax annual income at mean. And senior residents are defined as those who are 65 years old or above.

The OLS regression results are given in table 2 . The results show that health care expenditure positively depends on tax income, number of people per household, percentage of senior residents, percentage of minority residents, and residents' education level.

According to the t-ratio, variables $Y, N, S$, and $M$ are statistically significant at 5\% level, yet $E d u$ is somewhat significant (at $15 \%$ level). The results match with our expectation to some extent. We certainly expect annual health care expenditure positively correlate with income, percentage of senior residents, and residents' education level. Yet it is interesting to see that number of residents per household and percentage of minority residents are also important factors to determine the individual's health care expenditure. Given that the average residents per household is 3.44, and the fact that most Chinese couple only have one child, a higher number of residents per household means more senior residents in the household. Unlike in the US, it is very common and traditional that young couples live with their parents in order to take care of them, plus sometimes they need their parents to take care of their kid when they go to work. This could explain why health care expenditure is higher in the provinces where average number of residents per household is larger. As for the minority factor, it may be because that Chinese government has special policy to provide more health care services to the minorities comparing to the Han nation.

Table 2: OLS parameter estimates

\begin{tabular}{|l|c|c|c|}
\hline & Estimates & Std. Err. & t-ratio \\
\hline Per capita after tax annual income & 0.041 & 0.014 & 2.86 \\
\hline Number of residents per household & 286.4 & 132.0 & 2.17 \\
\hline Percentage of senior residents & 59.45 & 27.07 & 2.20 \\
\hline Percentage of minority residents & 3.934 & 1.863 & 2.11 \\
\hline \% of residents with college education & 18.11 & 12.00 & 1.51 \\
\hline Constant & -1731 & 596.6 & -2.90 \\
\hline Total sum of squared errors & 819351 & & \\
\hline F-statistic (5, 23) & 9.31 & & \\
\hline
\end{tabular}

\section{CONCLUSION}

In this paper, we use province level data to show that health care expenditure in China went down right after the reform of health care system in 2000, and then gradually went up and exceeded the level prior to the reform. We also show that health care expenditure are positively related to annual income, number of residents per household, percentage of senior residents, percentage of minority residents, as well as residents' education level. Since Chinese people are getting higher annual income nowadays, and more and more people have opportunities to get higher education, our model indicates that the health care expenditure will keep rising. The government should accordingly increase the supply of health care services to balance the rising demand of the services. 


\section{REFERENCES}

[1] Chow, Gregory C. (2006). "An Economic Analysis of Health Care in China", CEPS Working Paper, No. 132, Princeton University.

[2] Guo, Youde and Huanhua Wang (2002). "A Reconsideration of the Health Care Insurance Reform in China", Population and Economics, additional issue, Oct. 2002, pages 159-161 (in Chinese).

[3] Wang, Jie et al (2007). "Primary Care Reform in the Peoples' Republic of China: Implications for Training
Family Physicians for the World's Largest Country", Regional Reports - Asia, 39(9):639-643.

[4] Ramesh, M., Xun Wu, and A lex Jingwei He (2014). "Health Governance and Healthcare Reforms in China", Health Policy and Planning, 29(6):663-672.

[5] Fang, Hai, Qingyue Meng, and John A. Rizzo (2014). "Do Different Health Insurance Plans in China Create Disparities in Health Care Utilization and Expenditures?" International Journal of Applied Economics, 11(1):1-18. 